\title{
MOREAU SANFORD MAXWELL (1918-1998)
}

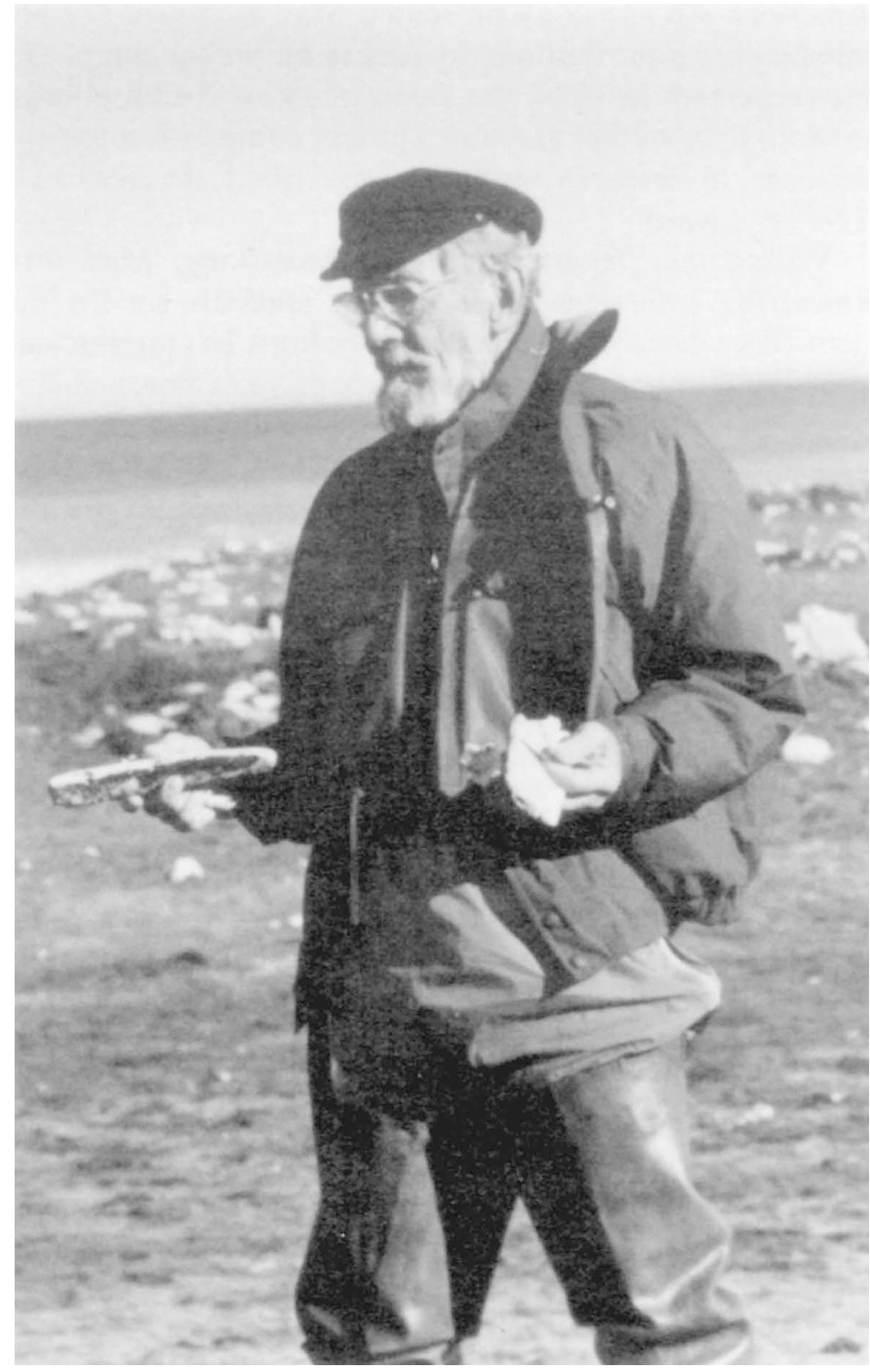

Moreau Maxwell on Baffin Island in the 1980s. Photo courtesy of the Maxwell Family.

Moreau Sanford Maxwell (Max), Emeritus Professor of Anthropology and Emeritus Curator of Anthropology at Michigan State University, died at his home on 30 January 1998 after a short struggle with cancer. Max was a devoted husband and father, an intrepid field archaeologist, an unparalleled storyteller, and a consummate teacher; his legacy remains indelibly imprinted on all who knew him. Max's varied career paths provided abundant fodder for his storytelling and his class lectures, made him a popular teacher with undergraduates, and earned him the reputation of raconteur par excellence among his colleagues. His stories, in whole and in part, will live on in their retelling by those of us who first heard them over campfires and in bars, over dinners, and on trips to meetings.

Moreau Maxwell's fascination with archaeology began when he was in high school in Schenectady, New York, where, under the auspices of the New York Archaeological Society, he participated in the excavation of Laurentian
Archaic sites in upstate New York. Max derived great glee from the fact that he never graduated from high school, matriculating at the University of Chicago under progressive admissions policies following his junior year. While an undergraduate, he participated in the 1936 University of Arizona excavations at the Bloody Basin Site, and subsequently in the 1938 University of Chicago excavations at the Kincaid site, where he mastered the Chicago Method. Completing his AB in 1939, Max entered the graduate program in anthropology at the University of Chicago. After a brief period of course work, he began the more than two years of Works Project Administration (WPA)-sponsored field and lab work in the Crab Orchard Basin of southern Illinois that would become the focus of his doctoral dissertation. His dissertation research was interrupted, however, by the onset of World War II. He served as a U.S. Navy dive bomber pilot in the Pacific Theatre, attaining the rank of Lieutenant (jg).

Shortly following his discharge from the service, Max received his M.A. from the University of Chicago in 1946, and his Ph.D. in 1949. By the time he received the Ph.D., he had already been appointed to the faculty at Beloit College in Wisconsin, where he devoted himself to three seasons of excavation at the Diamond Bluff and Aztalan sites between 1948 and 1950. In 1951 his dissertation, entitled Woodland Cultures of Southern Illinois, was published through the Logan Museum of Anthropology at Beloit. This work remains a standard reference in Midwestern archaeology.

From 1952 to 1957, employed by the U.S. Air Force, Max engaged in field ethnography as part of the Arctic, Desert, Tropical Information Center (ADTIC), located at Maxwell Air Force Base in Alabama. While some of this work carried him to Burma, Thailand, Vietnam, and Cambodia, the majority of his effort was devoted to projects at or above $70^{\circ} \mathrm{N}$ latitude. There he engaged in ethnography and Defense Early Warning system (DEW) Line siting, first as a civilian member of the U.S. Air Force Eclipse Project and then as Assistant Project Officer of the DEW Line Ice Survey Team. Max would tell stories, verified by his service records, of traveling with Inuit guides by dogsled along the 70th parallel to assess the ice at landing strip locations which would be used for DEW Line construction. His service records make particular note of a one-day flight Max made from Goose Bay, Labrador to Fairbanks, Alaska when temperatures at the surface were $-40^{\circ} \mathrm{F}$. It was during this period that he first observed archaeological evidence of Pre-Dorset and Dorset occupation in the High Arctic.

In 1957 Max joined the faculty of the Department of Sociology and Anthropology at Michigan State University, and became the first Curator of Anthropology at the Michigan State University Museum. He subsequently served as the first chair of the newly formed and independent Department of Anthropology from 1964 through 1969. 
As the inaugural chair, he applied his abundant administrative skills to building a solid faculty and program.

Moreau Maxwell's first Arctic archaeological research took place during a five-month period in 1958 , when, as a member of a Defense Research Board group participating in Canada's International Geophysical Year, he conducted an archaeological survey of the Lake Hazen vicinity on Ellesmere Island at $83^{\circ} \mathrm{N}$. He reported on this work in 1960.

During his tenure at Michigan State University, Max spent better than 15 field seasons in the Arctic, almost always with National Science Foundation funding, applying ecological and ethnoarchaeological approaches to PreDorset, Dorset, and Thule adaptations. From 1960 on, Max focused his research on Baffin Island, primarily in the Kimmirut (Lake Harbour) and Iqaluit (Frobisher Bay) vicinities, but also at Markham Bay and the Savage Islands. He published a detailed monograph on this work through the National Museum of Man in 1973. Max and his family spent the 1964-65 academic year in Denmark on a Fulbright Foundation Fellowship to the National Museum of Denmark, which allowed him to work with the Igloolik collections of Arctic archaeologist Jorgen Meldgaard. During this period, Max emerged as a prominent synthesizer of eastern Arctic archaeology, editing a Society for American Archaeology Memoir in 1976, reviewing the then-current status of Arctic and Subarctic archaeology in 1980 for the Annual Review of Anthropology, and publishing the landmark work Prehistory of the Eastern Arctic in 1985. While Arctic research consumed Max throughout his career and into his retirement, he occasionally returned to Midwestern archaeology. Of particular note is his pioneering work in Great Lakes historical archaeology. He conducted three seasons of field research at Fort Michilimackinac, published with Lewis Binford as Excavation at Fort Michilimackinac, Mackinac City, Michigan, 1959 Season, and two seasons of salvage work at the Fletcher site.

Moreau Maxwell's consistent record of research, administration, teaching, publication, grantsmanship, and university service earned him the Michigan State
University Distinguished Faculty Award in 1975. In 1985, on the occasion of its 50th Anniversary, The Society for American Archaeology presented Max an award for his outstanding contributions to American archaeology. On his retirement in 1984, the Department of Anthropology instituted an annual graduate student competition for excellence in research, eponymously titled the Maxwell Scholar Award.

Within the Department of Anthropology, Max was known by colleagues and graduate students for his indepth knowledge of general anthropology. His intellectual contributions to seminars, comprehensive exams, and dissertation defenses were among the highlights of graduate education for numerous students at Michigan State University. As a consequence of his prolonged Arctic research, and the abundant respect he had for the indigenous peoples of the region, Max maintained lifelong friendships with the Inuit among whom and with whom he worked. As his colleagues will attest, mutual respect prevailed.

After retiring from Michigan State University in 1984, Max continued to read proposals, review articles, and correspond with his Arctic colleagues and new generations of students. He even began yet another career as a shipboard lecturer on Arctic cruises!

Max is survived by Eleanor, his wife of 54 years, his children Moreau Jr., Alan, John, and Tia, and his four grandchildren. He will be missed by all who knew him, friends, students, and colleagues. It was my privilege to have been all three.

The Department of Anthropology has established the Moreau S. Maxwell Memorial Lecture Series in his memory. Donations should be made out to Michigan State University and mailed to the MSU Department of Anthropology.

William A. Lovis Curator and Professor of Anthropology MSU Museum and Department of Anthropology Michigan State University East Lansing, Michigan, U.S.A. 48824 